\title{
Morphological features of bone regeneration in simulated refracture of growing long bones
}

\author{
A.A. Kosimov' ${ }^{1}$, I.Iu. Khodzhanov¹, E.N. Gorbach², T.A. Silant'eva², O.V. Diuriagina ${ }^{2}$, D.Yu. Borzunov ${ }^{2,3}$ \\ ${ }^{1}$ Republican Specialized Scientific and Practical Medical Center of Traumatology and Orthopaedics, Tashkent, Uzbekistan, \\ ${ }^{2}$ Russian Ilizarov Scientific Center for Restorative Traumatology and Orthopaedics, Kurgan, Russian Federation, \\ ${ }^{3}$ Tyumen State Medical University, Tyumen, Russian Federation
}

\begin{abstract}
Introduction Long bone refractures can be a common injury among pediatric population. Approaches to rehabilitation of children with refractures are similar to those used for primary injuries. However, refracture healing and bone repair involve specific pathways that should be considered in rehabilitative approaches to restorative treatment. Objective To identify morphological specific features of simulated reparative processes in long bone refractures of growing animals (rats) at different stages of observation. Material and methods Two series of experiments were carried out on 36 laboratory animals (rats) to explore histological picture at the healing site of primary and repeat fractures at different stages of reparative process. Transverse fracture of the tibial shaft was simulated and fixed with external fixation device in the first series $(\mathrm{n}=18)$. Tibial shaft was refractured and fixed again with external fixation device after 21 days of primary injury in the second series $(n=18)$. Results Delayed osteogenesis and greater period of organotypical regenerate restructuring were observed in animals with long bone refractures. Mechanism of slower osteogenesis was found to be associated with disturbed blood supply affecting cell differentiation at the refracture site. Conclusion Delayed bone repair and longer period of organotypical regenerate restructuring were specifically detected in growing animals with long bone refractures.

Keywords: growing animal, rat, long bone, refracture, reparative osteogenesis
\end{abstract}

\section{INTRODUCTION}

Long bone refractures can be a common injury among pediatric population and constitute $57.6 \%$ of total pediatric skeletal injuries [1-3]. Conventional conservative and surgical treatment with minimally invasive surgery are employed by orthopaedic surgeons to restore bone integrity. The gold standard surgical tool for pediatric fractures requiring fixation is elastic stable intramedullary nailing (ESIN) [4-6]. Delayed consolidation and nonunion are reported in 0.5-3.2 \% of the cases, whereas refractures after ESIN occur in 4.9-6.7 \% of children [7-10]. Pediatric refractures are reported to range between $4 \%$ and $21.3 \%$ [11-14]. Approaches to rehabilitation of children with refractures are similar to those used for primary injuries. It should be noted that pediatric refractures are often treated either by general surgeons or general practitioners at local hospitals. There is a paucity of literature, Russian in particular, exploring long bone refractures in pediatric population $[15,16]$. However, refracture healing and bone repair involve specific pathways that should be considered in rehabilitative approaches to restorative treatment. A lack of a unified approach to the treatment strategy can be associated with shortage of information on reparative processes of long bone refractures.

Objective To identify morphological specific features of simulated reparative processes in long bone refractures of growing animals (rats) at different stages of observation.

\section{MATERIAL AND METHODS}

Thirty-six male and female Wistar rats aged 5-6 months and weighing 306-506 g were used in experiment. The animals were divided into two experimental series. The manipulations were produced in accordance with The European Convention for the protection of vertebrate animals used for experimental and other scientific purposes and Order of the Ministry of Health of the USSR dtd $12^{\text {th }}$ August 1977 No. 755 on Follow-on development of organizational forms of practices using experimental animals.

Primary transverse fracture of the tibial shaft was simulated and fixed with external fixation device in the first experimental series $(n=18)$. Morphological examination was performed on day 35 of bone fixation ( $n=6$ ), 28 (63 days of the experiment, $n=6$ ) days and on day 49 after frame removal (84 days

Kosimov A.A., Khodzhanov I.Iu., Gorbach E.N., Silanteva T.A., Diuriagina O.V., Borzunov D.Yu. Morphological features of bone regeneration in simulated refracture of growing long bones. Genij Ortopedii, 2019, vol. 25, no 4, pp. 555-560. DOI 10.18019/10284427-2019-25-4-555-560. (In Russian) 
of experiment, $n=6$ ). Refracture of the tibial shaft and external re-fixation of the bone were produced in the second series after 21 days of the primary fracture simulation $(n=18)$. Examinations were performed after 21 days of fixation (21 days of the experiment, $\mathrm{n}=6$ ); 35 days of simulated refracture (56 days of the experiment, $\mathrm{n}=6$ ); 28 days after frame removal (84 days of the experiment, $n=6$ ). Surgical procedures were performed under general anesthesia and sterile conditions. Anesthesia was induced with solution of $2 \% 8 \mathrm{mg} / \mathrm{kg}$ rometar and 4 $\mathrm{mg} / \mathrm{kg}$ zoletil-100. Tibial regenerate bones of the rats were histologically examined. Specimen were fixed in $10 \%$ neutral buffered formalin during 14 days, decalcified in Richman-Gelfand-Hill solution, dehydrated in solutions of increasing alcohol concentration and embedded in paraffin. Histological preparations (paraffin sections of 5-7 mcm cut with Reichard sledge microtome (Germany)) were stained with hematoxylin and eosin, and Masson's trichrome. Images of micropreparations were acquired with AxioCam digital camera, AxioScope.A1 microscope and Zen blue software (Carl Zeiss MicroImaging $\mathrm{GmbH}$, Germany).

\section{RESULTS}

Histological healing characteristics of the primary tibial fractures of rats in the settings of stable external fixation. Bone consolidation was observed after 35 days of primary fracture simulated in the tibial shaft in the settings of stable external fixation. The regenerate bone had normotrophic structure (Fig. 1a) with continuous compact plate of honeycombed cancellous bone peripherally formed between regenerate bone fragments in the intermediary and periosteal zones (Fig. 2a).
Vascularized spongious connective tissue were seen in intertrabecular spaces with chondroid foci spread somewhere. Osseous tissue formed in the intermediary part of the diastasis had reticulofibrous structure. Bone trabeculae and hemapoietic-fatty bone marrow with prevailed hemapoietic component was observed in the intramedullary cavity at the fracture site (Fig. 2d). Osteoclasts attached to the surface of bone trabeculae were indicative of organotypical restructuring.
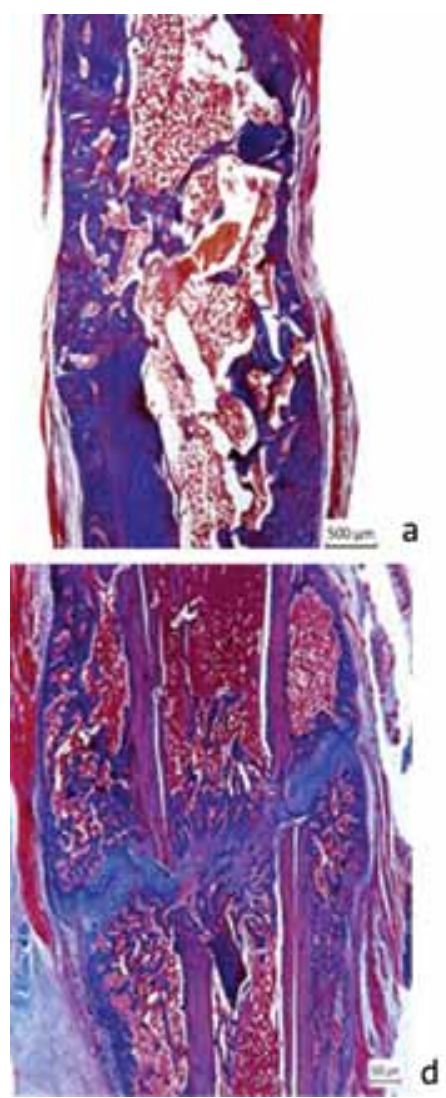
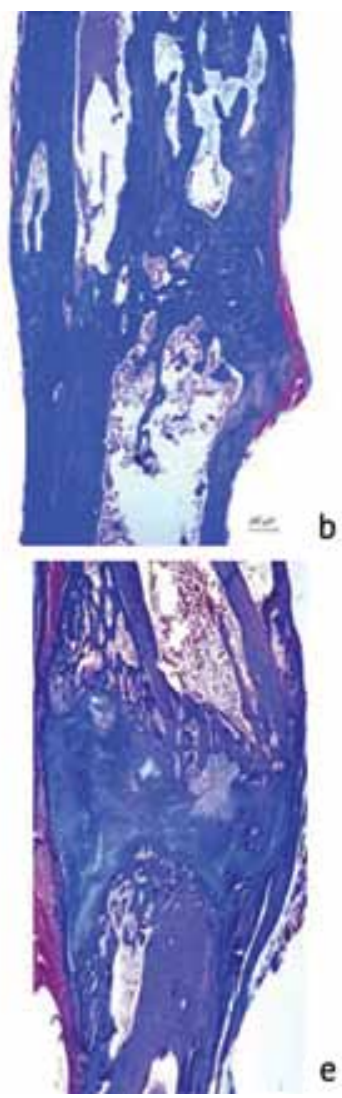
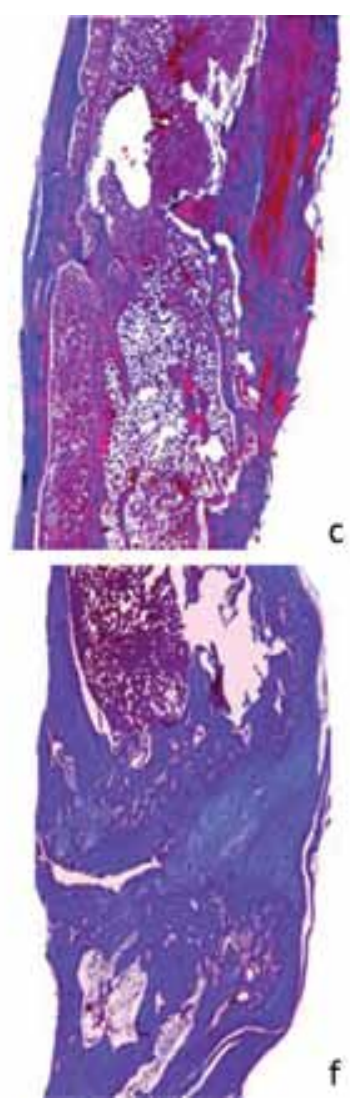

Fig. 1 Histological structure of the tibial shaft of a rat at the site of the primarily simulated fracture with adjacent bone fragments showing bone consolidation and organotypical bone restructuring developing in the 1st series of experiment $(\boldsymbol{a})$ after 35 days of external fixation (35 days of experiment); (b) 28 days after frame removal (63 days of expriement); (c) 49 days after frame removal (84 days of experiment); fibrous and cartilage bone consolidation and nonunion observed in the 2 nd series of simulated refracture (d) after 21 days of external fixation of the simulated tibial refracture (21 days of experiment); $(\boldsymbol{e})$ after 35 days of external re-fixation ( 56 days of experiment); (f) 28 days after frame removal (84 days of experiment). Paraffin sections stained with Masson's trichrome. Magnified by 25× 
Bone resorption was not evident with osteogenesis being more expressed at the site. The Haversian canals of bone fragments appeared to be slightly widened. Moderately expressed endosteal and periosteal reaction was observed proximally and distally the fracture. Mesobrochate and honeycombed cancellous bone was seen in the perosteal layers. Endosteum appeared as a coarse mesh formed by bone trabeculae from endosteal side. Bone marrow cavity was filled with red-yellow bone marrow with preveiling fatty component.

Compact bone with lamellar structure was seen in the intermediary site of the interfragmental diastasis after 35 days of external fixation and 28 days after frame removal (Fig. 1b; 2b). The bone connecting the fragments was characterized by compact structure with small cavities filled with vessels surrounded by spongious connective tissue. Periosteal reaction was not evident. Persistent endosteal reaction revealed glomerular net of trabecular bone in the bone marrow canal (Fig. 2e). Hemapoietic-fatty bone marrow was observed at the fracture site with fatty component prevailing at the bone fragments. Sinusoid extended capillaries with hemocytes in the lumen were seen in the intramedullary cavity at the fracture site. Haversian canals of the compact bone appeared to be narrow as compared to the previous time period.
Continuous compact plate and bone marrow cavity were observed to form at the consolidation site 49 days after frame removal (Fig. 1c). Lamellar structure and primarily typical osteon orientation were characteristic for intermediary part of the new bone (Fig. 2b). Intramedullary cavity was filled with red-yellow bone marrow with resorptive bone trabeculae (Fig. 2f). Hemopoietic component was primarily seen in the intramedullary cavity of the new bone and fat was detected in the bone fragment cavity. Bone marrow vessels were not much plethoric as compared to the previous time period of experiment. Periosteal reaction was not evident and endosteal reaction was more expressed. Compact plate of the fragments was dense enough with singular Haversian canals being moderately widened.

Histological healing characteristics of the tibial refractures of rats in the settings of stable external fixation. By the time of simulated refracture fibrousbone-cartilage consolidation was observed in the tibial diastasis of animals of the second series after 21 days of primary tibial fixation with external device (Fig. 1d). Fragments of fibrous cartilaginous, fibrous and reticulofibrous bone tissue were observed in the intermediary zone (Fig. 3a). Ossifying cartilaginous tissue was mainly seen in the endosteum (Fig. 3d). Osteoclasts appeared to adhere to the surface of the new coarse fibrous bone trabeculae.
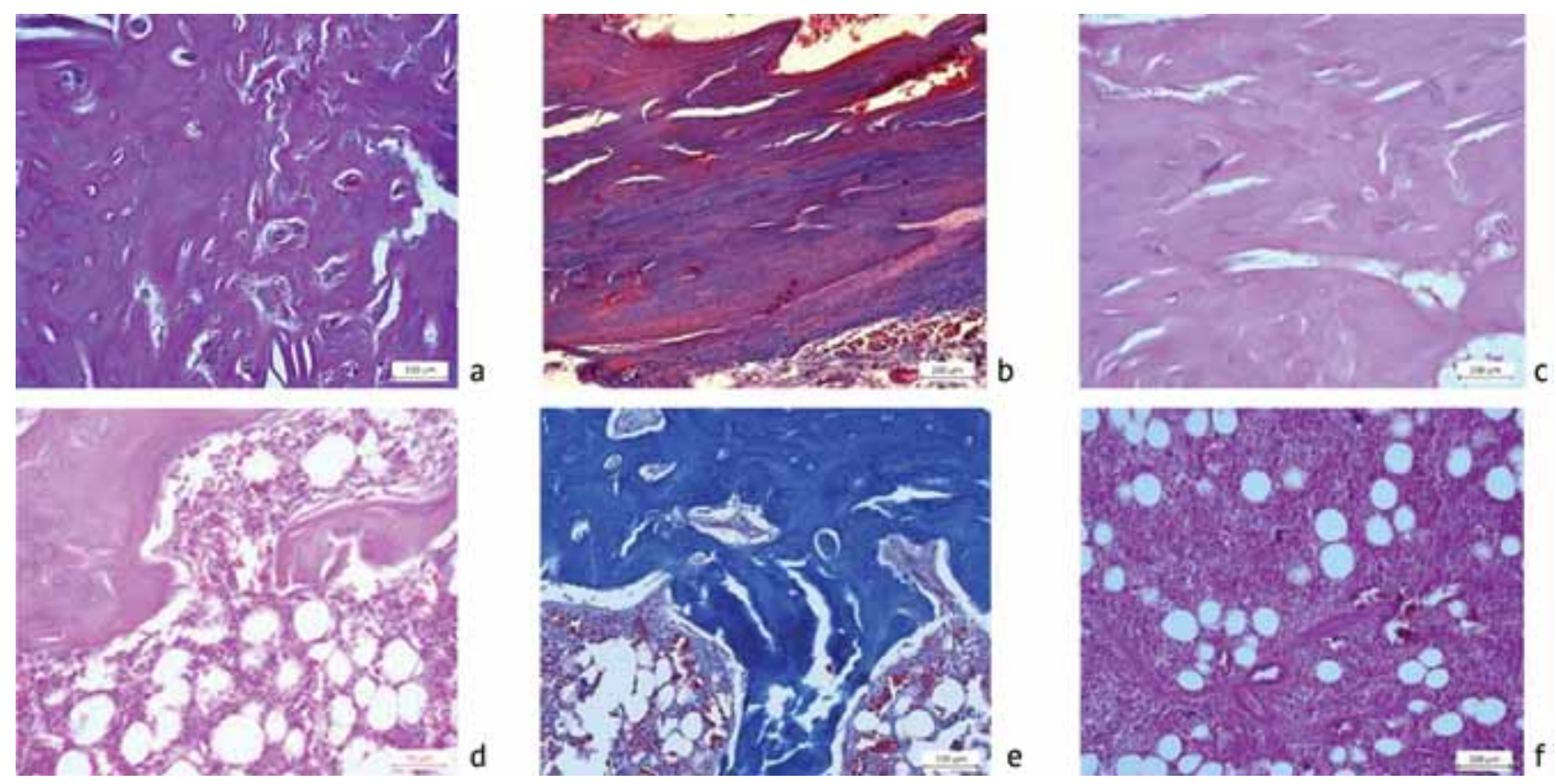

Fig. 2 Morphology of the tibial consolidation in the first experimental series of the primary fracture simulated in the tibial shaft of a rat showing honeycombed cancellous bone with reticulofibrous structure formed in the intermediary part of the healed fracture after 35 days of external fixation $(\boldsymbol{a})$ that appeared to get more compact with external fixation device taken off after $63(\boldsymbol{b})$ and 84 (c) days of experiment. Hemapoietic-fatty bone marrow and endosteally formed bone trabeculae were seen in the intramedullary cavity of the new bone at the same time periods of experiment $(\boldsymbol{d}, \boldsymbol{e})$ that underwent resorption at the end of experiment $(\boldsymbol{f})$. Paraffin sections stained with hematoxylin and eosin $(\boldsymbol{a}, \boldsymbol{c}, \boldsymbol{d}, \boldsymbol{f})$ and Masson'trichrome $(\boldsymbol{b}, \boldsymbol{e})$. Magnified by $200 \times(\boldsymbol{a}, \boldsymbol{b}, \boldsymbol{c}) ; 400 \times(d, e, f)$ 

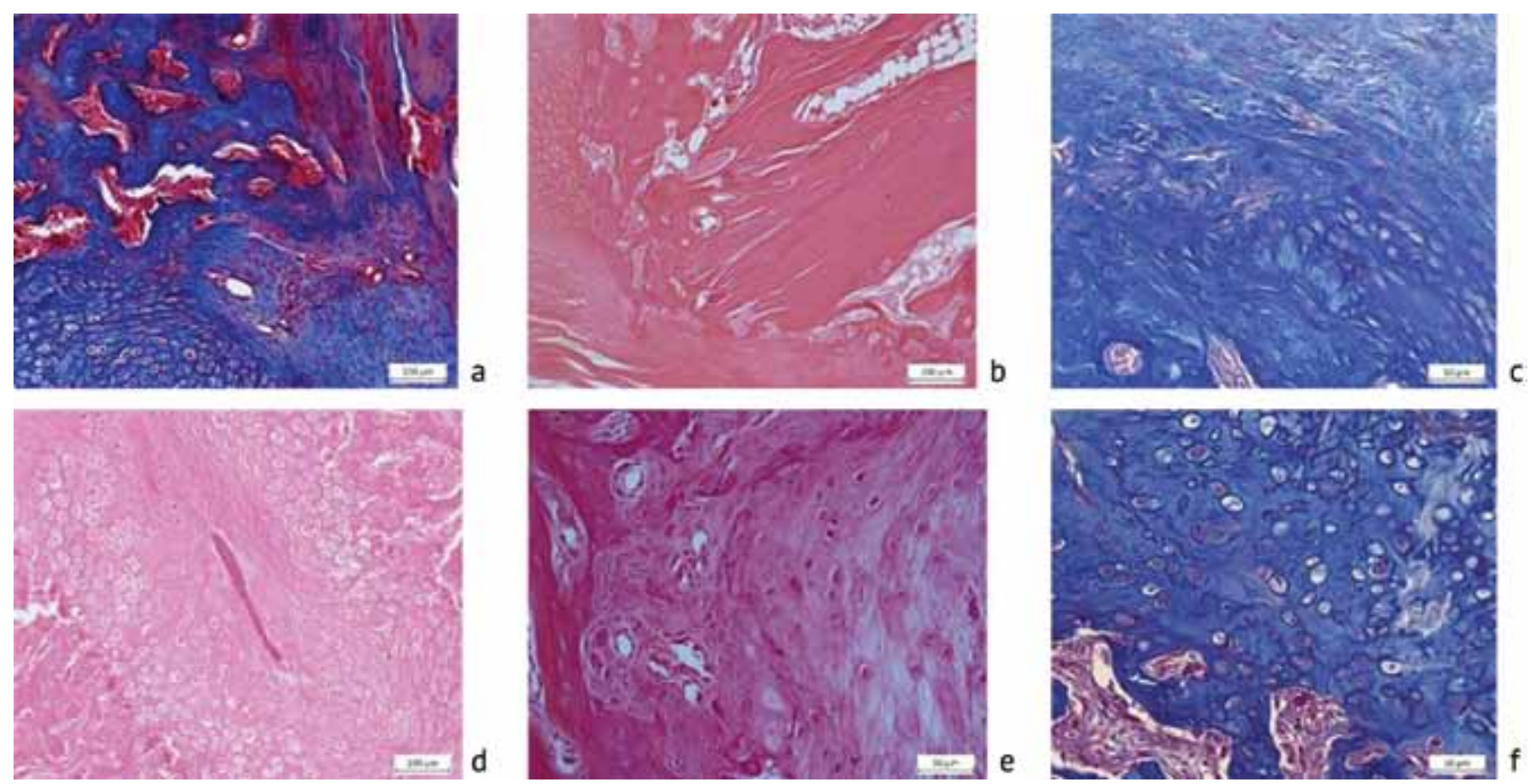

Fig. 3 Morphology of the tibial consolidation in the second experimental series of a refracture simulated in the tibial shaft of a rat showing fibrous cartilage being ossified in the intermediary diastatis by the time of simulated refracture after 21 days of external fixation $(\boldsymbol{a})$. Desmo-, chodro- and osteogenesis was seen after 56 days of experiment, 35 days of refixation with external fixation device $(\boldsymbol{b})$; fibrous-cartilaginous consolidation of bone fragments were observed after 84 days of experiment, 28 days after frame removal $(\boldsymbol{c})$. Areas of cartilaginous tissue were identified in the endosteal portion of consolidation $(\boldsymbol{d}-\boldsymbol{f})$ with signs of vascular invasion and indolent reparative osteogenesis at the boundary of bone fragments. Paraffin sections stained with hematoxylin and eosin $(\boldsymbol{b}, \boldsymbol{d}, \boldsymbol{e})$ and Masson'trichrome $(\boldsymbol{a}, \boldsymbol{c}, \boldsymbol{f})$. Magnified by $200 \times$

Periosteal reaction on the surface of bone fragments spread proximally and distally as far as 6 to $7 \mathrm{~mm}$ off the fracture site. Thickness of the periosteal callus was $0.5-1.0 \mathrm{~mm}$. Consolidation site was mostly presented with fibrous cartilage at the borderline with areas of reticulofibrous trabecular bone and chondroid (Fig. 3e). Spongious fibrous connective tissue with areas of hemopoiesis and extended synusoid capillaries were observed in intertrabecular spaces of the spongy bone tissue. Haversian canals of the compact plate appeared to be slightly extended and filled with poorly vascularized spongious connective tissue. Hemopoietic bone marrow with incorporated adipocytes were primarily seen in the intramedullary cavity of tibial fragments. There were several reticulofibrous bone trabeculae and extended plethoric microvessels observed in the canal.

Fibrous-osseous-cartilaginous consolidation of bone fragments were noted in the diastasis after tibial refracture and 35-day refixation with external fixation device (Fig. 1e). Foci of fibrous tissue, fibrous cartilage and trabecular bone were seen in the intermediary, endosteal and periosteal parts of the regenerate bone (Fig. 3 b, e). Periosteal callus was large measuring 5 $\mathrm{mm}$ in length and $2.0-2.7 \mathrm{~mm}$ in thickness presenting mesobrochate and honeycombed cancellous bone tissue at the fragments' level. Intertrabecular spaces were filled with vascularized spongious fibrous connective tissue and microvessels. Hemopoietic fatty bone marrow with resorption of the wound surfaces was seen in the intramedullary canal of bone fragments. Periosteal callus included fibrous cartilaginous tissue over the span of $1.5-2.0 \mathrm{~mm}$ at the fracture site. Ingrowing microvessels accompanied by bands of reticulofibrous trabecular tissue that were replaced with a strap of fibrous cartilaginous tissue $500-600 \mathrm{mcm}$ high in the middle of the regenrate bone were observed in intramediary and endosteal zones at the borderline with fragments. Fibrous cartilaginous tissue appeared to transform into chondroid at the vascular ingrowth site (Fig. 3e).

Osseous-cartilaginous consolidation with areas of fibrous connective tissue containing singular cavities was seen in interfragmental diastasis after 35 days of refixation and 28 days after frame removal (Fig. 1f). Areas of nonvascularized fibrous cartilage and connective tissue were detected on the anterior surface of the bone at the consolidation site (Fig. 3c). Indolent formation of honeycombed cancellous bone substance providing partial bone healing in the posterior aspect of the bone was observed in intermediary and endosteal parts of consolidation at the borderline with proximal 
and distal fragments (Fig. 3f). Trabecular surface was resorbed with multiple adherent osteoclasts that was indicative of remodelling of the new bone. Compact plate of bone fragments was perforated with multiple extended Haversian canals filled with spongious connective tissue. Red-yellow bone marrow was seen in intertrabecular spaces of the new osseous substance and intramedullary canal of bone fragments. Impaired microcirculation was observed with hyperemic vessels of the microcirculation bed and vascular stasis.

Thus, the findings demonstrated that fibrousosseous-cartilaginous consolidation occurred in the diastasis with accurate bone reduction and stable fracture fixation of the tibial shaft of the rats after
21 days. The healing was shown to be unable to sustain axial loading and result in refracture. With stable fixation ensured for 35 days fibrous-osseouscartilaginous callus appeared to being subject to restructuring and be replaced with osseous tissue that became more compact in the intermediary and periosteal zones of healing after frame removal. Animals of the second series with refractured tibiae developed fibrous-osseous-cartilaginous healing of bone fragments after 35 day refixation with predominant fibrous cartilage. Indolent osteogenesis and fibrous-cartilaginous nonunion were observed at the healing site 28 days after removal of external fixation device.

\section{DISCUSSION}

Some researchers suggest that longer time period is required for reliable bone healing after refracture 17]. Although refractures are more common in the first 10 months refractures that occur 18 months after injury are more problematic [18, 19]. Our findings indicated to delayed reparative processes and longer period of organotypical restructuring of the regenerate bone forming in interfragmental diastasis of long bones after refracture. Mechanism of delayed osteogenesis is thought to be associated with disturbed blood supply at microcirculation that is important for migration of multipotent less differentiated cells to the fracture site and their osteogenic differentiation [20]. Organotypical restructuring of bone callus, additional immobilization and protective regime are essential for prevention of refractures. Immobilization of the forearm for 6 weeks facilitates 4-to-6-fold decrease in risk of refracture [21]. The strategy of pediatric refractures is contraversial. Either nonoperative treatment with longer immobilization using plaster cast for 2-3 months [18] or differentiated approach with use of surgical techniques can be offered for the repair of refractures [22]. Evaluating current treatment modalities we can suggest that intramedullary osteosynthesis can be the treatment of choice for refractures of long bones facilitating anatomical and functional restoration of bone integrity within a short period of time. Bone recanalization with closed reaming of sclerotic bone is an important aspect of the technique representing a noninvasive method of closed bone autologous grafting to improve trophics of tissues at the refracture site.

\section{CONSLUCSION}

Delayed bone repair and longer period of organotypical regenerate restructuring were specifically detected in refracture healing of tibial shaft of experimental animals that developed complete bone consolidation with external fixation following primary tibial fracture. The findings can be useful when choosing a surgical treatment option.

\section{REFERENCES}

1. Korobeinikov A.A., Popkov D.A. Analiz oshibok i oslozhnenii pri lechenii diafizarnykh perelomov kostei predplechia u detei metodom intramedulliarnogo elastichnogo stabilnogo osteosinteza [Analysis of errors and complications when treating shaft fractures of forearm bones in children by the method of intramedullary elastic stable osteosynthesis]. Travmatologiia i Ortopediia Rossii, 2016, vol. 22, no. 2, pp. 25-33. (in Russian)

2. Lascombes P., Nespola A., Poircuitte J., Popkov D., De Gheldere A., Haumont T., Journeau P. Early complications with flexible intramedullary nailing in childhood fracture: 100 cases managed with precurved tip and shaft nails. Orthop. Traumatol. Surg. Res., 2012, vol. 98, no. 4, pp. 369-375. DOI:10.1016/j.otsr.2011.11.011.

3. Parikh S.N., Jain V.V., Denning J., Tamai J., Mehlman C.T., McCarthy J.J., Crawford A.H. Complications of elastic stable intramedullary nailing in pediatric fracture management: AAOS exhibit selection. J. Bone Joint Surg. Am., 2012, vol. 94, no. 24, pp. e184.1-e184.14. DOI:10.2106/JBJS.L.00668.

4. Lascombes P., Huber H., Fay R., Popkov D., Haumont T., Journeau P. Flexible intramedullary nailing in children: nail to medullary canal diameters optimal ratio. J. Pediatr. Orthop., 2013, vol. 33, no. 4, pp. 403-408. DOI:10.1097/BPO.0b013e318285c54d. 
5. Popkov D., Lascombes P., Popkov A., Journeau P., Haumont T. Role of the flexible intramedullary nailing in limb lengthening in children: Comparative study based on the series of 294 lengthenings. European Orthopaedics and Traumatology, 2012, vol. 3, no. 1, pp. 17-24. DOI:10.1007/s12570-012-0090-1.

6. Korobeinikov A.A., Pervuninskaya Ju.E., Popkov D.A. Angular stability of intramedullary elastic osteosynthesis. Biomedical Engineering, 2016, vol. 49, no. 6, pp. 370-374. DOI:10.1007/s10527-016-9569-3.

7. Ballal M.S., Garg N.K., Bruce C.E., Bass A. Nonunion of the ulna after elastic stable intramedullary nailing for unstable forearm fractures: a case series. J. Pediatr. Orthop. B, 2009, vol. 18, no. 5, pp. 261-264. DOI:10.1097/BPB.0b013e32832f0648.

8. Weinberg A.M., Castellani C., Arzdorf M., Schneider E., Gasser B., Linke B. Osteosynthesis of supracondylar humerus fractures in children: A biomechanical comparison of four techniques. Clinical Biomechanics, 2007, vol. 22, no. 5, pp. 502-509. DOI:10.1016/j. clinbiomech.2006.12.004.

9. Lascombes P. Flexible intramedullary nailing in children: The Nancy University Manual. Berlin, Heidelberg, Springer-Verlage, 2010, 317 p. DOI:10.1007/978-3-642-03031-4.

10.Van Egmond P.W., Van der Sluijs H.A., Van Royen B.J., Saouti R. Refractures of the paediatric forearm with the intramedullary nail in situ. BMJ Case Rep., 2013, DOI:10.1136/bcr-2013-200840.

11.Bairov G.A., Baindurashvili A.G. Povtornye perelomy [Repeated fractures]. Bairov G.A., red. Detskaia Travmatologiia: monografiia. 2-e izd. [Pediatric Traumatology: monograph. $2^{\text {nd }}$ Ed.]. SPb., Piter, 2000, ch. 17, pp. 327-329. (in Russian)

12.Kuzmin B.P. Povtornye perelomy obeikh kostei predplechia u detei [Repeated fractures of both forearm bones in children]. Ortopediia, Travmatologiia i Protezirovanie, 1967, no. 8, pp. 70-72. (in Russian)

13.Fernandez F.F., Langendörfer M., Wirth T., Eberhardt O. Failures and complications in intramedullary nailing of children's forearm fractures. J. Child. Orthop., 2010, vol. 4, no. 2, pp. 159-167. DOI:10.1007/s11832-010-0245-y.

14.Carey T.P., Galpin R.D. Flexible intramedullary nail fixation of pediatric femoral fractures. Clin. Orthop. Relat. Res., 1996, vol. 332, pp. 110-118. DOI:10.1097/00003086-199611000-00015.

15.Lascombes P., Poncelet T., Lesur E., Prévot J., Blanquart D. Repeat fractures of the 2 forearm bones in children. Rev. Chir. Orthop. Reparatrice Appar. Mot., 1988, vol 74, no. Suppl. 2, pp. 137-139.

16.Ochs B.G., Gonser C.E., Baron H.C., Stöckle U., Badke A., Stuby F.M. Refracture of long bones after implant removal. An avoidable complication? Unfallchirurg, 2012, vol. 115, no. 4, pp. 323-329. DOI:10.1007/s00113-012-2155-6.

17.Tisosky A.J., Werger M.M., McPartland T.G., Bowe J.A. The factors influencing the refracture of pediatric forearms. J. Pediatr. Orthop., 2015, vol. 35, no. 7, pp. 677-681. DOI:10.1097/BPO.0000000000000355.

18.Baitner A.C., Perry A., Lalonde F.D., Bastrom T.P., Pawelek J., Newton P.O. The healing forearm fracture: a matched comparison of forearm refractures. J. Pediatr. Orthop., 2007, vol. 27, no. 7, pp. 743-747. DOI:10.1097/BPO.0b013e318142568c.

19.Park H.W., Yang I.H., Joo S.Y., Park K.B., Kim H.W. Refractures of the upper extremity in children. Yonsei Med. J., 2007, vol. 48, no. 2, pp. 255-260. DOI:10.3349/ymj.2007.48.2.255.

20.Fong E.L., Chan C.K., Goodman S.B. Stem cell homing in musculoskeletal injury. Biomaterials, 2011, vol. 32, no. 2, pp. 395-409. DOI: 10.1016/j.biomaterials.2010.08.101.

21.Bould M., Bannister G.C. Refractures of the radius and ulna in children. Injury, 1999, vol. 30, no. 9, pp. 583-586. DOI:10.1016/ S0020-1383(99)00151-5.

22.Kosimov A.A., Khodzhanov I.Iu. Otdalennye rezultaty lecheniia povtornykh perelomov kostei u detei [Long-term results of treatment for refractures in children]. Genij Ortopedii, 2014, no. 1, pp. 41-45. (in Russian)

Received: 29.07.2019

\section{Information about the authors:}

1. Azam A. Kosimov, M.D., Ph.D.,

Republican Specialized Scientific and Practical Medical Center of Traumatology and Orthopaedics, Tashkent, Uzbekistan,

Email: azamrefracture@mail.ru

2.Iskandar Yu. Khodzhanov, M.D., Ph.D., Professor,

Republican Specialized Scientific and Practical Medical Center of Traumatology and Orthopaedics, Tashkent, Uzbekistan

3. Elena N. Gorbach, Ph.D. of Biological Sciences,

Russian Ilizarov Scientific Center for Restorative Traumatology and Orthopaedics, Kurgan, Russian Federation,

Email: gorbach.e@mail.ru

4. Tamara A. Silant'eva, Ph.D. of Biological Sciences,

Russian Ilizarov Scientific Center for Restorative Traumatology and Orthopaedics, Kurgan, Russian Federation, Email: tsyl@mail.ru

5.Olga V. Diuriagina, Ph.D. of Veterinary Sciences,

Russian Ilizarov Scientific Center for Restorative Traumatology and Orthopaedics, Kurgan, Russian Federation,

Email: diuriagina@mail.ru

6. Dmitry Yu. Borzunov, M.D., Ph.D.,

Russian Ilizarov Scientific Center for Restorative Traumatology and Orthopaedics, Kurgan, Russian Federation, Tyumen state medical university, Tyumen, Russian Federation,

Email: borzunov@bk.ru 